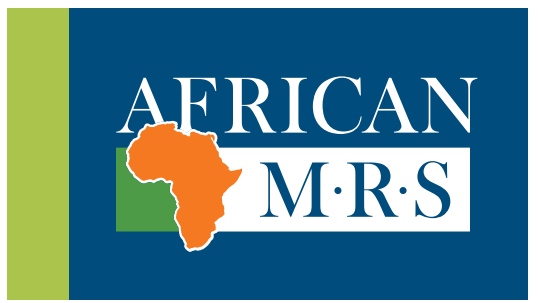

\title{
Addressing Africa's challenges through materials development
}

\author{
https://amrsbotswana.org • http://www.bitri.co.bw/cms
}

$T^{\mathrm{n}}$ he African Materials Research Society (AMRS) held its 9th International Conference this past December in Gaborone, Botswana. The meeting was largely organized by the Botswana Institute for Technology Research and Innovation (BITRI). Thanks to the tireless efforts of Samuel Chigome, secretary of the local organizing committee, and the leadership of Nelson Torto, chair of the committee, AMRS2017 was a resounding success.

AMRS was conceived in 2000 at a USA-Africa Materials workshop held in South Africa. The US National Science Foundation (NSF) and the South

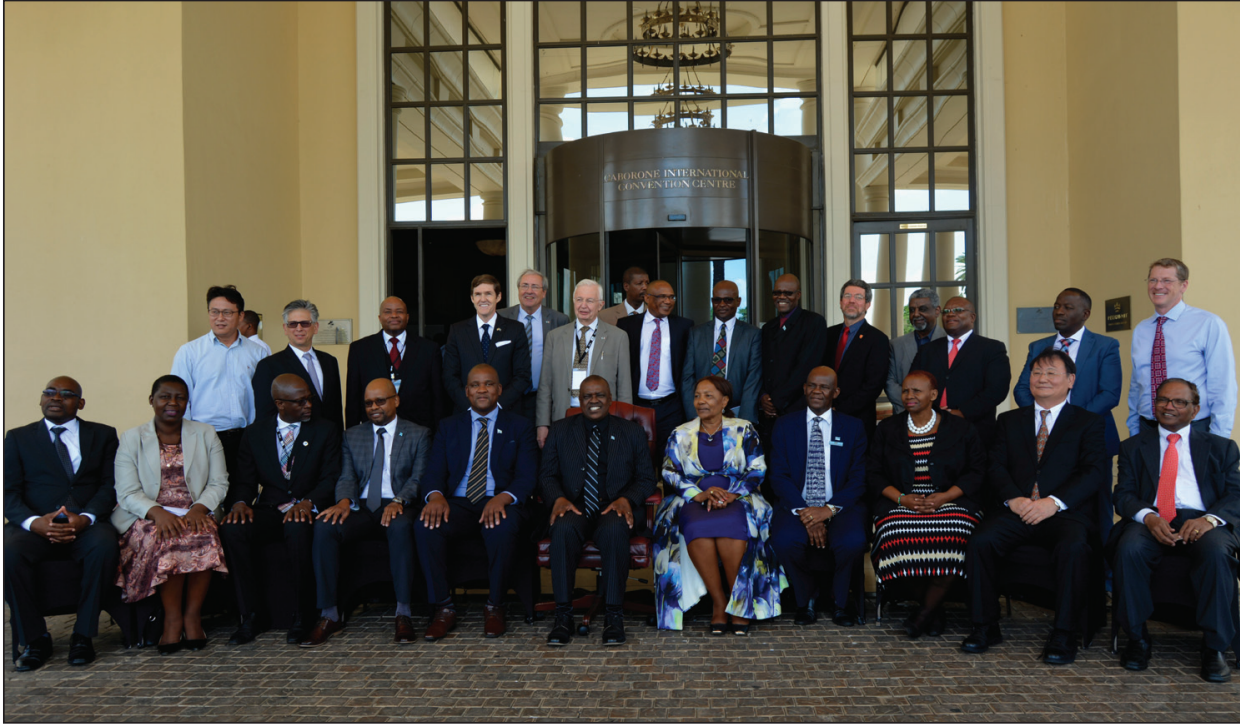

AMRS dignitaries, including the vice president of Botswana, government officials, BITRI board members, invited speakers, and conference organizers, at the opening reception.

African National Research

Foundation (NRF) co-organized and co-sponsored the workshop. Participants explored opportunities for collaboration between the United States and Africa, with the overarching objective of developing the materials research capacity in Africa. Building on this initiative, AMRS was officially launched two years later in 2002 in Senegal, home to the first AMRS International Conference. Students and professionals from around the world, with expertise in the many facets of materials science, engineering, and research, attended the conference.

Since 2003, AMRS has held biannual international conferences. The meeting has moved among locations across the African continent, including Victoria Falls, Zimbabwe; Addis Ababa, Ethiopia; and Accra, Ghana. Symposia themes have broadly covered the areas of energy, environment, health, nanotechnology, computational materials science, mineral processing, construction, and materials education, usually with a focus on areas that are relevant to African development. At the most recent Gaborone meeting, a theme focused on materials for agriculture was introduced. Enthusiasm for this new direction was high, as evidenced by the high quality of speakers.

The AMRS meetings have maintained an upward trajectory in both attendance and excellence, as exemplified by the outstanding plenary speakers at AMRS 2017. The meeting was kicked off by inspirational words from the Vice President of Botswana, Mokgweetsi Masisi, who discussed the importance of technological innovation in materials for the nation's and indeed continent's development. Nobel Laureate Jean-Marie Lehn (Chemistry, 1987) then described the path of his research career and challenged the audience members to engage each other with broad, encompassing questions. The other four plenary speakers were Tobin Jay Marks (Northwestern University), Sossina M. Haile (Northwestern Univer- sity), Paul Weiss (University of California, Los Angeles), and Nelson Torto (African Academy of Sciences). In all, approximately 315 oral presentations and 150 poster presentations were delivered, with an attendance of more than 500 from 45 different countries and representation from five continents. This large number of registrants translated into successful attendance in the meetings rooms, and lively discussions could be heard at both the oral and poster sessions.

Prior to the main conference, eight pre-conference workshops, covering topics ranging from electrospinning and light microscopy to crystallography and scanning electron microscopy, were held at the BITRI Centre for Materials Science (CMS). The workshop facilitators were a mix of university faculty members, who had come to Gaborone for the AMRS conference, and representatives from equipment suppliers for the institute. Almost 200 people attended the 
workshops, the large majority of whom were graduate students. The workshop participants not only benefited from advanced training in the practical aspects of performing their research, but also gained an appreciation for the top-quality facilities available at BITRI CMS. The institute boasts, for example, a high-resolution Zeiss GeminiSEM 500 Field Emission Gun Electron Microscope, as well as a Kratos Axis Supra X-ray Photoelectron Spectrometer. The institute is a hub of electrospinning, as evidenced by two electrospinning labs with state-of-the-art electrospinning units. Two of the seven units are pilot scale: the Elmarco Nanospider NS1WS500U and Bioinicia LE500. Many workshop attendees expressed their interest in returning to the institute as visiting researchers as part of their future work.

Student participation was a key focus of AMRS2017. At least 80 students received sponsorships to attend the pre-conference workshops and conference from the Royal Society of Chemistry, American Chemical Society, Microscopy Society of America,
MRS, AMRS, African Network of Analytical Chemists, Institute of Development Management, NSF via the Joint Undertaking for an African Materials Institute, and Elmarco. For many of the student participants, it was their first time attending a scientific conference, and the international representation made the event even more significant.

The papers presented at AMRS2017 are invited for inclusion in a dedicated issue of MRS Advances, which will serve as the official depository for the Proceedings of the 9th International Conference. MRS Advances, published jointly by MRS and Cambridge University Press, is a peer-reviewed online journal that reports snapshots of work in progress on key materials topics, focusing, in particular, on the proceedings of conferences in materials research. AMRS participants are enthusiastic for this new partnership.
Complete information about the conference is available at https:// amrsbotswana.org. Information about BITRI CMS is available at www.bitri. co.bw/cms.

The activities of AMRS have been strongly supported since its inception by the US NSF and, in recent years, by MRS. All participants gratefully acknowledge this support.

Sossina M. Haile

(with input from Samuel Chigome and Eric Garfunkel)

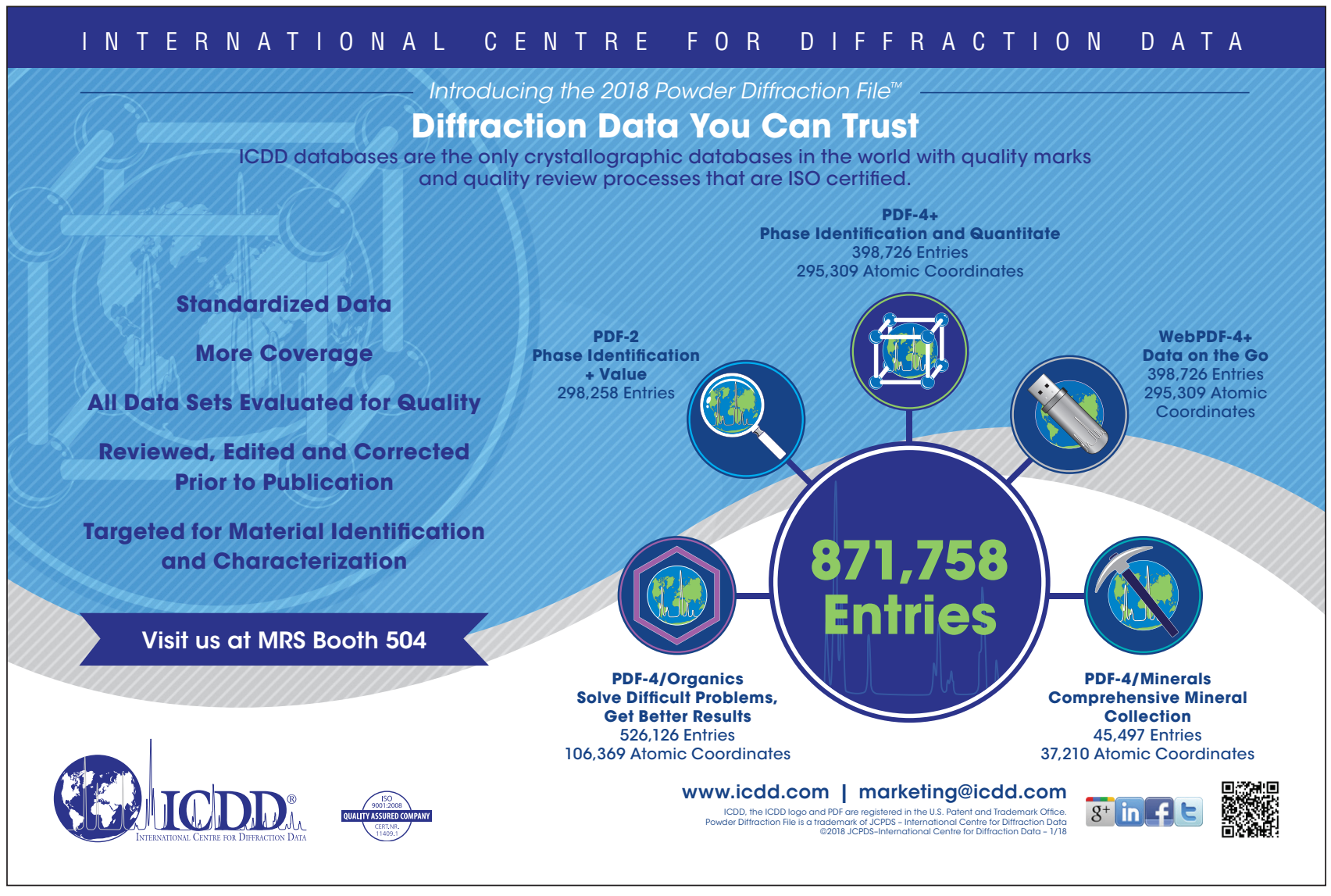




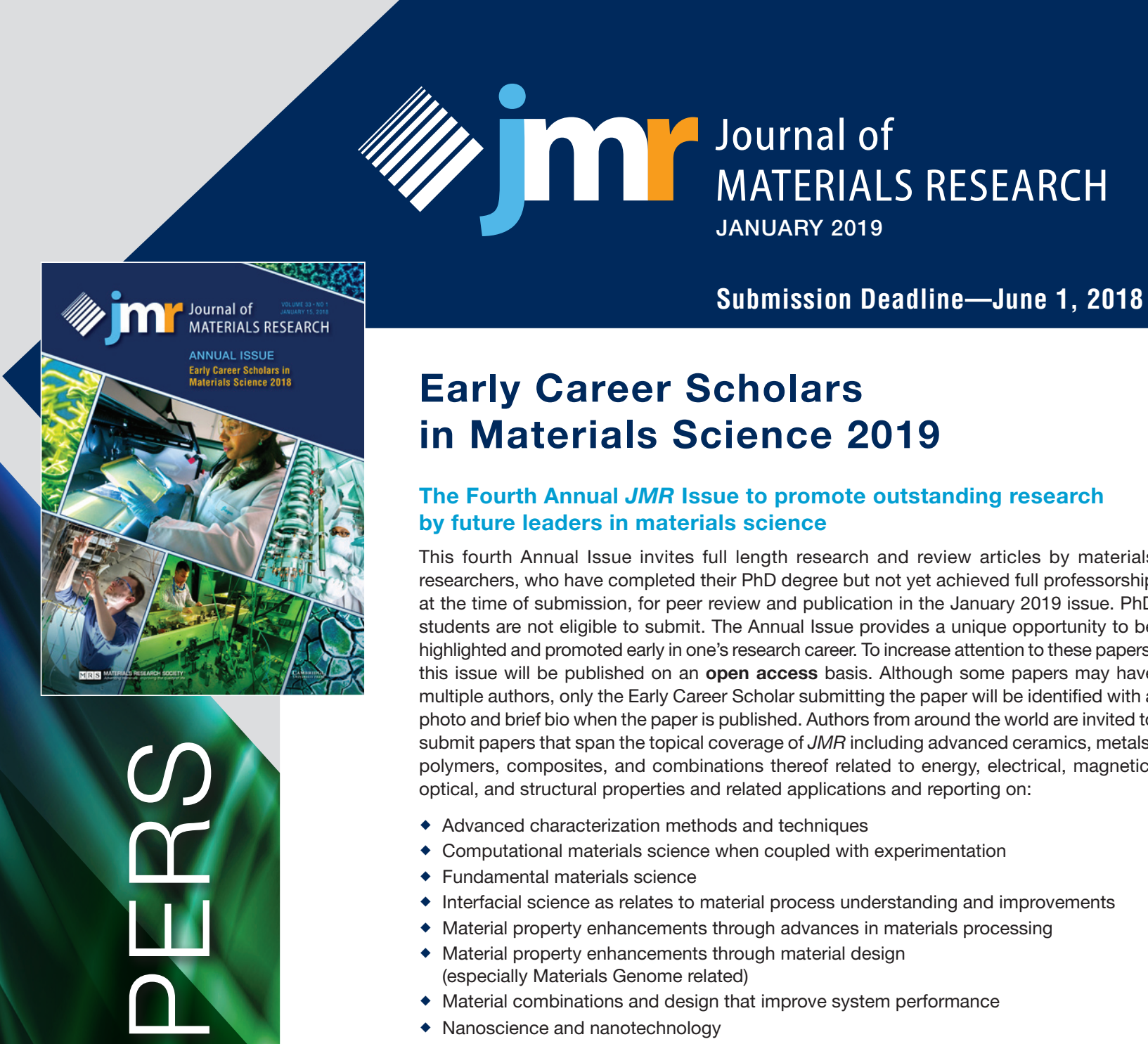

LEAD EDITORS

Gary L. Messing, Pennsylvania State University, USA

Susmita Bose, Washington State University, USA

Jürgen Eckert, Montanuniversität Leoben, Austria

Linda S. Schadler, Rensselaer Polytechnic Institute, USA

\section{MANUSCRIPT SUBMISSION}

To be considered for the issue, the Early Career Scholar must not yet be a full professor at the time of submission. Also, the manuscript must report new and previously unpublished results. Review articles are invited but must be approved by the issue editors before submission (see www.mrs.org/jmr-manuscript-types/ regarding review articles). Manuscripts must be submitted via the JMR electronic submission system by June 1, 2018. Manuscripts submitted after this deadline will not be considered for the issue due to time constraints on the review process. Submission instructions can be found at www.mrs.org/jmr-instructions. Please select "ANNUAL ISSUE: Early Career Scholars in Materials Science 2019" as the manuscript type. Note our manuscript submission minimum length of 3250 words, with at least 6 and no more than $\mathbf{1 0}$ figures and tables. (Additional figures and tables may be submitted as supplemental material.) All manuscripts will be reviewed in a normal but expedited fashion. Papers submitted by the deadline and subsequently accepted will be published in the Special Issue. Other manuscripts that are acceptable but cannot be included in the issue will be scheduled for publication in a subsequent issue of $J M R$.

Papers must be accompanied by a photo (uploaded separately as a high resolution TIF or EPS file) and 200-300 word bio of the Early Career Scholar only. These materials must be submitted along with the original submission of the paper.

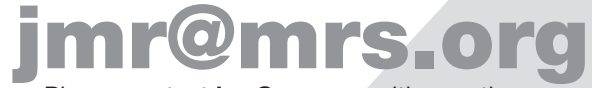

Please contact jmr@mrs.org with questions. 

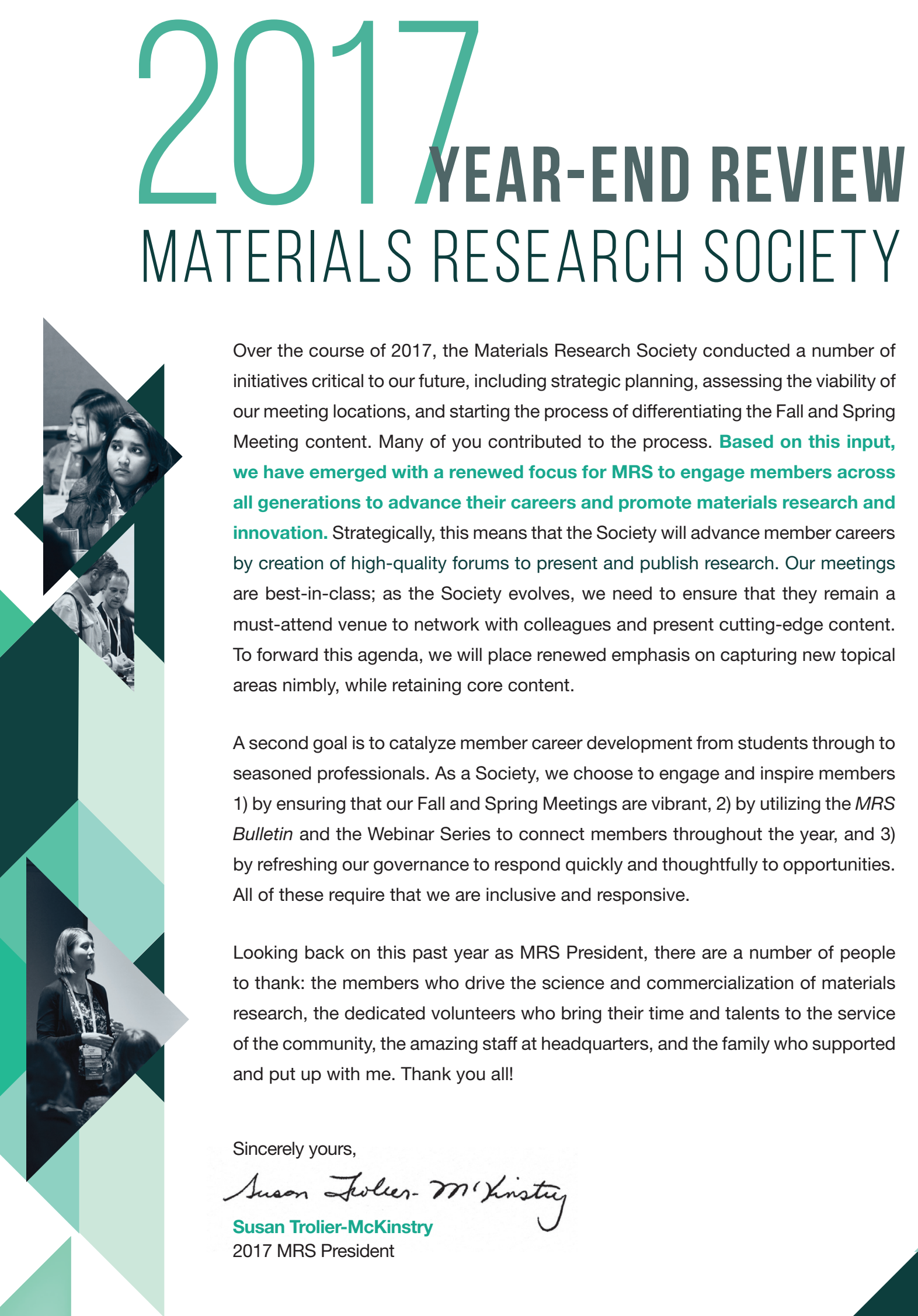

Over the course of 2017, the Materials Research Society conducted a number of initiatives critical to our future, including strategic planning, assessing the viability of our meeting locations, and starting the process of differentiating the Fall and Spring Meeting content. Many of you contributed to the process. Based on this input, we have emerged with a renewed focus for MRS to engage members across all generations to advance their careers and promote materials research and innovation. Strategically, this means that the Society will advance member careers by creation of high-quality forums to present and publish research. Our meetings are best-in-class; as the Society evolves, we need to ensure that they remain a must-attend venue to network with colleagues and present cutting-edge content. To forward this agenda, we will place renewed emphasis on capturing new topical areas nimbly, while retaining core content.

A second goal is to catalyze member career development from students through to seasoned professionals. As a Society, we choose to engage and inspire members 1) by ensuring that our Fall and Spring Meetings are vibrant, 2) by utilizing the MRS Bulletin and the Webinar Series to connect members throughout the year, and 3) by refreshing our governance to respond quickly and thoughtfully to opportunities. All of these require that we are inclusive and responsive.

Looking back on this past year as MRS President, there are a number of people to thank: the members who drive the science and commercialization of materials research, the dedicated volunteers who bring their time and talents to the service of the community, the amazing staff at headquarters, and the family who supported and put up with me. Thank you all!

Sincerely yours,

Ausan Julues- m'Kinstuy 2017 MRS President 


\section{BY THE}
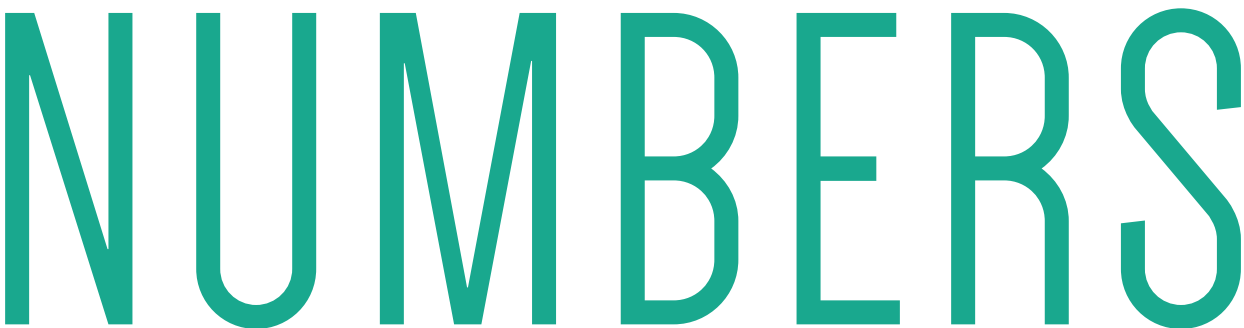

Looking back on 2017, we are delighted to see all the Materials Research Society has accomplished. Our members, volunteers, exhibitors, sponsors, partners and headquarters staff are all to thank for the tremendous success of our Society. We are pleased to present this year-end review, outlining some of our biggest achievements of the past year ... by the numbers!

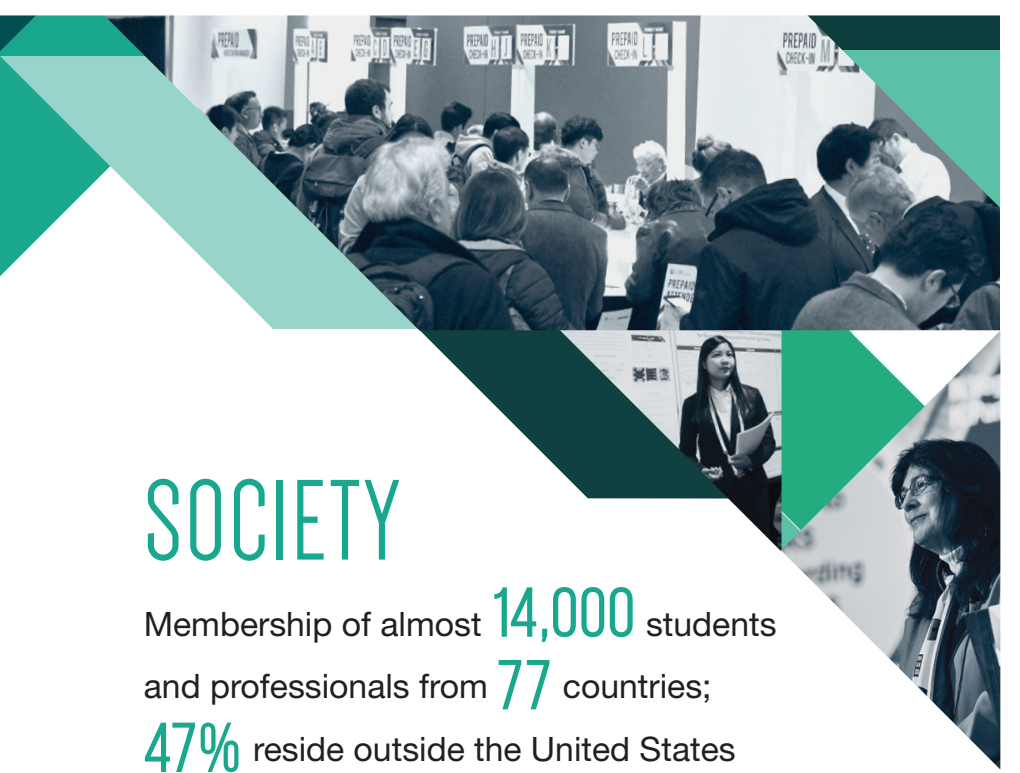

9 new MRS University Chapters, bringing current total to $117 ; 19 \%$ located outside the United States

\section{MRS Corporate Partners}

Record-breaking 97 members honored through the MRS Awards Program

Over 1000 volunteers from around the world help to advance $1 \mathrm{M}|\mathrm{SS}| \mathrm{ON}$ - to promote communication for the advancement of interdisciplinary materials research and technology to improve the quality of life

\section{PUBLICATIONS}

With 2017 Impact Factor of 5.199, MRS Bulletin ranked in top $15 \%$ of materials science journals

Journal of Materials Research (JMR) sustained impressive cited half-life of $>10$ YEARS

2017 Impact Factor for MRS Communications increased by $68 \%$ to 3.01

In 1ST year of eligibility, MRS Advances indexed in Web of Science, Emerging Sources Citation Index (ESCl)

Based on Altmetric Attention Score,

MRS Energy \& Sustainability ranked $3 \mathrm{RD}$ among competing journals

MRS Book Collection grew to 19 books/ textbooks

MRS OnDemand ${ }^{\circledR}$ Webinar Series produced 13 live webinars, reaching over 2500 participants in 50 countries 


\section{MEETINGS \& EVENTS}

107 topical symposia and 346 international exhibitors featured at 2017 MRS Spring and Fall Meetings; total on-site attendance topped 12,250

2017 MRS Spring and Fall Meetings offered 6194 oral presentations, 3852 poster presentations and 21 tutorial sessions

17 teams selected for 4TH iMatSci Innovation Showcase; over 550 attended the iMatSci events

Record 1866 from 46 countries attended the XXVI International Materials Research Congress (IMRC), held in partnership with the Sociedad Mexicana de Materiales (SMM)

3 conference events, with 58 exhibitors and over 1260 attendees, managed through the MRS Conference Services Program 


\section{MATERIALS RESEARCH SOCIETY FOUNDATION}

Your donations to the Materials Research Society Foundation support a wide range of initiatives that support our members and the materials community. Citing just a few highlights of 2017 , the Foundation:

Introduced the newly endowed

\section{MRS NELSON "BUCK" ROBINSON SCIENCE AND TECHNOLOGY AWARD FOR RENEWABLE ENERGY}

Application is open to students, postdocs or other young professionals engaged in novel sustainable solutions for renewable energy technology. The inaugural Award will be presented at the 2018 MRS Fall Meeting.

supported 117 MRS UNIVERSITY CHAPTERS WORLDWIDE, funded seven University Chapter Special Projects, and hosted a two-day International Summit of the MRS University Chapters on Sustainability and Nanotechnology

Expanded our PROFESSIONAL DEVELOPMENT AND CAREER SERVICES PORTFOLIO with seminars and workshops that include Essentials of Getting Your Work Published, Preparing for Your Next Job Interview, Negotiating a Job Officer, Green Cards for Scientific Researchers, Using Improv for Communications, and more.

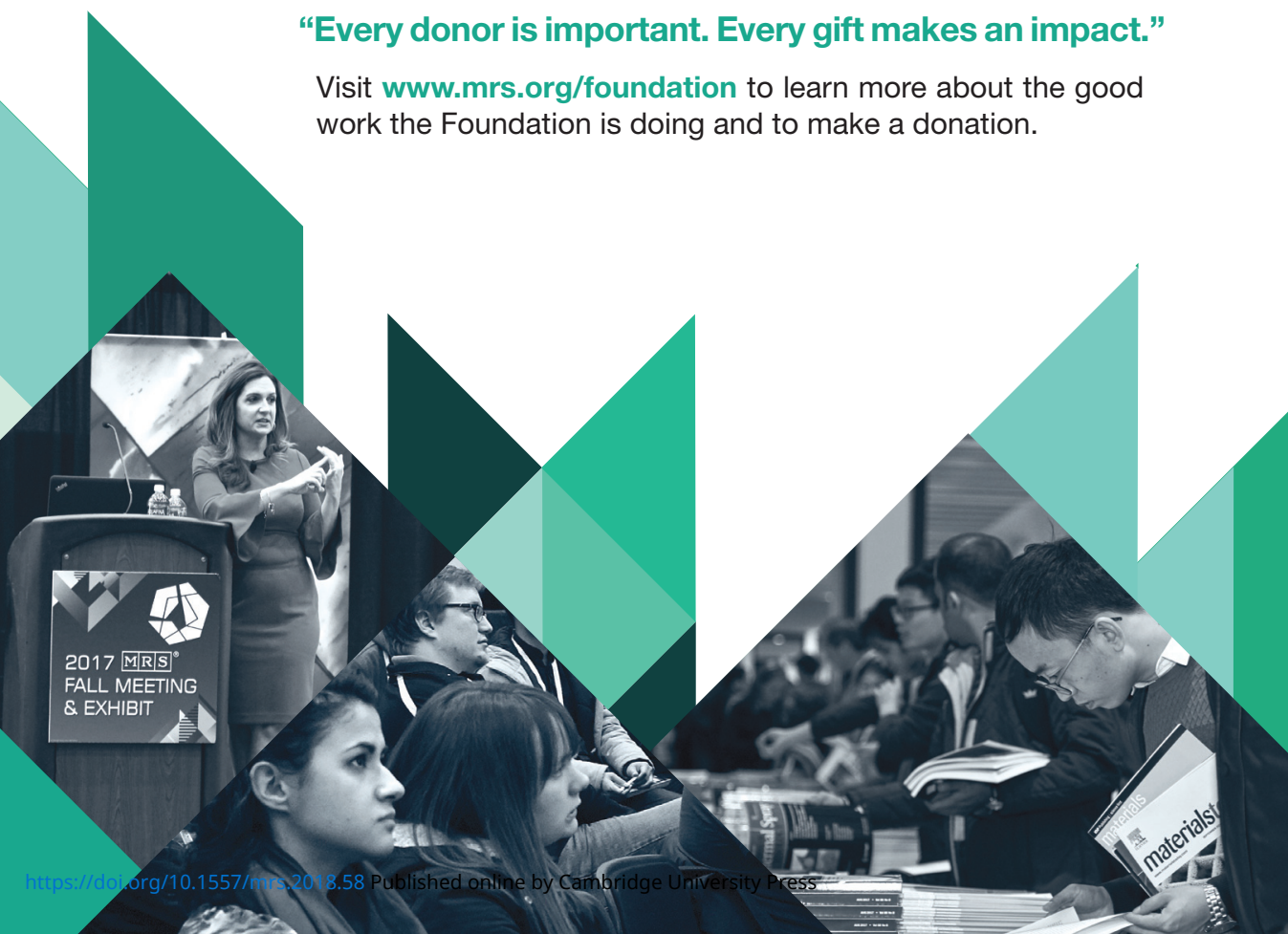

\section{MRS Officers}

President

Susan Trolier-McKinstry

The Pennsylvania State University

Immediate Past President

Kristi S. Anseth

University of Colorado Boulder

Vice President/President-Elect

Sean J. Hearne

Sandia National Laboratories

Secretary

Eric A. Stach

University of Pennsylvania

Treasurer

David J. Parrillo

The Dow Chemical Company

Executive Director

Todd M. Osman

Materials Research Society

\section{MRS Board of Directors}

Charles T. Black

Brookhaven National Laboratory

L.C. Chen

National Taiwan University

Matt Copel

IBM T.J. Watson Research Center

Paul S. Drzaic

Apple, Inc.

Dawnielle Farrar-Gaines

Johns Hopkins University

Yury Gogotsi

Drexel University

Claudia Gutiérrez -Wing

Instituto Nacional de Investigaciones

Nucleares (ININ)

Young-Chang Joo

Seoul National University

Karen L. Kavanagh

Simon Fraser University

Lincoln J. Lauhon

Northwestern University

Christine Ortiz

Massachusetts Institute of Technology

Sabrina Sartori

University of Oslo

Magaly Spector

The University of Texas at Dallas

Molly M. Stevens

Imperial College London

Anke Weidenkaff

University of Stuttgart

\section{Committee Chairs}

ACADEMIC AFFAIRS COMMITTEE

Albert Polman

FOM Institute AMOLF

ACADEMIC AFFAIRS COMMITTEE

Bruce M. Clemens

Stanford University

GOVERNMENT AFFAIRS COMMITTEE

Kevin J. Whittlesey

4D Molecular Therapeutics

MEETINGS COMMITTEE

Terry Aselage

Sandia National Laboratories

MEMBER ENGAGEMENT COMMITTEE

Sossina M. Haile

Northwestern University

PUBLIC OUTREACH COMMITTEE

Elizabeth Kupp

The Pennsylvania State University

PUBLICATIONS COMMITTEE

Shefford P. Baker

Cornell University 


\section{$2018 \mathrm{M}|\mathrm{R}| \mathrm{S}{ }^{\circ}$ FALL MEETING \& EXHIBIT}

November 25-30, 2018 | Boston, Massachusetts
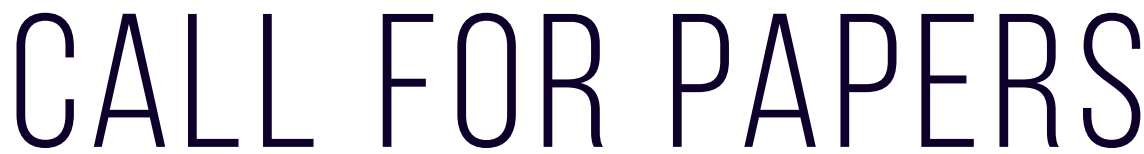

Abstract Submission Opens
May 14, 2018

Abstract Submission Deadline June 14, 2018

Fall Meeting registrations include MRS Membership January - December 2019

\section{BROADER IMPACT}

BI01 Sustainable Development in Materials Science and Related Societal Aspects

BI02 The Future of Materials Science Academia-

Preparing for a Career in Higher Education

\section{BIOMATERIALS AND SOFT MATERIALS}

BM01 3D Printing of Passive and Active Medical Devices

BM02 Electronic and Coupled Transport in Biology

BM03 Multiscale Modeling of Soft Materials and Interfaces

BM04 Biomaterials for Regenerative Engineering

BM05 Advanced Manufacturing Technologies for Emulating Biological Tissues

BM06 Plasma Processing and Monitoring for Bioengineering and Biomedical Engineering

BM07 Bioelectronics-Fundamentals, Materials and Devices

BM08 Materials-to-Devices for Integrated Wearable SystemsEnergy Harvesting and Storage, Sensors/Actuators and Integration

BM09 Bioinspired Macromolecular Assembly and Inorganic CrystallizationFrom Tissue Scaffolds to Nanostructured Materials

\section{CHARACTERIZATION, MECHANICAL PROPERTIES AND} STRUCTURE-PROPERTY RELATIONSHIPS

CM01 Solid-State Chemistry of Inorganic Materials

CM02 Structure-Property Relations in Non-Crystalline Materials

CM03 In Situ/Operando Analysis of Electrochemical Materials and Interfaces

CM04 Ultrafast Optical Probes for Advanced Materials Characterization and Development

CM05 Fundamentals of Materials Property Changes Under Irradiation

\section{ELECTRONIC, PHOTONIC AND MAGNETIC MATERIALS}

EP01 New Materials and Applications of Piezoelectric, Pyroelectric and Ferroelectric Materials

EP02 Materials for Manipulating and Controlling Magnetic Skyrmions

EP03 Beyond-Graphene 2D Materials-

Synthesis, Properties and Device Applications

EP04 Novel Photonic and Plasmonic Materials Enabling New Functionalities

EP05 Excitons, Electrons and Ions in Organic Materials

EP06 Coherent Electronic Spin Dynamics in Materials and Devices

\section{MEETING CHAIRS}

Kristen H. Brosnan GE Global Research

David LaVan National Institute of Standards and Technology

Patrycja Paruch University of Geneva

Joan M. Redwing The Pennsylvania State University

Takao Someya The University of Tokyo

\section{www.mrs.org/fall2018}

\section{8 iMatSci Innovator Showcase}

CALL FOR EARLY-STAGE STARTUPS

Submission Site Opens: June 1, 2018 www.mrs.org/imatsci
EP07 Tailored Disorder-Novel Materials for Advanced Optics and Photonics

EP08 Ultra-Wide-Bandgap Materials and Devices

EP09 Diamond Electronics, Sensors and BiotechnologyFundamentals to Applications

ENERGY-TRANSFER, STORAGE AND CONVERSION

ET01 Solid-State Batteries-Materials, Interfaces and Performance

ET02 Silicon for Photovoltaics

ET03 Application of Nanoscale Phenomena and Materials to Practical Electrochemical Energy Storage and Conversion

ET04 Perovskite Solar Cells-Challenges and Opportunities

ET05 Fundamental Aspects of Halide Perovskite (Opto)electronics and Beyond

ET06 Advanced Materials and Chemistries for High-Energy and Safe Rechargeable Batteries

ET07 Advanced Processing and Manufacturing for Energy Conversion, Storage and Harvesting Devices

ET08 Emerging Materials and Characterization for Selective Catalysis

ET09 Materials for Chalcogen Electrochemistry in Energy Conversion and Storage

ET10 Redox Active Materials and Flow Cells for Energy Applications

ET11 Emerging Materials and Device Concepts for Flexible, Low-Cost Photovoltaic Technologies

ET12 Harvesting Functional Defects in Energy Materials

ET13 Materials for Multifunctional Windows

ET14 Materials Science Facing Global Warming - Practical Solutions for Our Future

ET15 Scientific Basis for Nuclear Waste Management

\section{GENERAL INTEREST}

GI01 Machine Learning and Data-Driven Materials Development and Design

GI02 Materials for Next-Generation Robotics

\section{NANOMATERIALS}

NM01 Carbon Nanotubes, Graphenes and Related Nanostructures

NM02 Nanometal-Synthesis, Properties and Applications

NM03 Nanowires and Related 1D NanostructuresNew Opportunities and Grand Challenges

NM04 Nanomaterials and Nanomanufacturing for Sustainability

\section{PROCESSING AND MANUFACTURING}

PM01 Architected Materials-

Synthesis, Characterization, Modeling and Optimal Design

PM02 Conductive Materials Reliability in Flexible Electronics

PM03 Hierarchical, Hybrid and Roll-to-Roll Manufacturing for Device Applications

PM04 High-Entropy Alloys

PM05 Electromagnetic Fields in Materials Synthesis-Far from Equilibrium Effects

PM06 Advances in Intermetallic-Based Alloys for Structural and Functional Applications

PM07 Plasma-Based Synthesis, Processing and Characterization of Novel Materials for Advanced Applications

THERMAL PROPERTIES AND THERMOELECTRIC MATERIALS

TP01 Caloric Materials for Highly Efficient Cooling Applications

TP02 Thermal Analysis-Materials, Measurements and Devices

TP03 Emerging Low-Temperature Thermal Energy Conversion Technologies \begin{tabular}{l|l|l|l}
\hline & MATERIALS RESEARCH SOCIETY \\
Advancing materials. Improving the quality of life.
\end{tabular}

506 Keystone Drive • Warrendale, PA 15086-7573

Tel 724.779.3003 • Fax 724.779.8313

info@mrs.org • www.mrs.org 